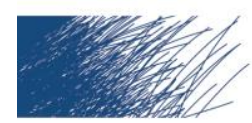

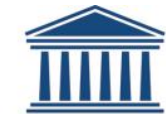 \\ UNIVERSITEIT GENT
}

biblio.ugent.be

The UGent Institutional Repository is the electronic archiving and dissemination platform for all UGent research publications. Ghent University has implemented a mandate stipulating that all academic publications of UGent researchers should be deposited and archived in this repository. Except for items where current copyright restrictions apply, these papers are available in Open Access.

This item is the archived peer-reviewed author-version of:

Title: Medial adjunct PPs in English: Implications for the syntax of sentential negation Authors: De Clercq, Karen, Liliane Haegeman \& Terje Lohndal

In: Journal, Volume (Issue), pages, year. Nordic Journal of Linguistics 35(1), 5-26..

To refer to or to cite this work, please use the citation to the published version:

De Clercq, Karen, Liliane Haegeman \& Terje Lohndal. 2012. Medial adjunct PPs in English: Implications for the syntax of sentential negation. Nordic Journal of Linguistics 35(1), 5-26..

\section{Medial adjunct PPs in English: Implications for the syntax of sentential negation}

Karen De Clercq, Liliane Haegeman, Terje Lohndal

This paper provides evidence that medial adjunct PPs in English are possible: On the basis of corpus data, it is shown that sentence-medial adjunct PPs are not unacceptable and are attested. Our corpus data also reveal a sharp asymmetry between negative and non-negative 
adjunct PPs. The analysis of the corpus revealed the following pattern: Non-negative adjunct PPs such as at that time resist medial position and instead tend to be post-verbal. Negative adjunct PPs such as at no time appear medially rather than postverbally. In the second part of the paper, we broaden the empirical domain and include negative complement PPs in the discussion. It is shown that when it comes to the licensing of question tags, English negative complement PPs, which are postverbal, pattern differently from postverbal negative adjunct PPs. That is, sentences with a postverbal negative adjunct PP pattern with negative sentences in taking a positive question tag, while sentences containing a postverbal negative argument PP pattern with affirmative sentences in taking a negative tag. To account for the observed adjunct-argument asymmetry in the licensing of question tags, we will propose that clauses are typed for polarity and we explore the hypothesis that a polarity head in the left periphery of the clause is crucially involved in the licensing of sentential negation.

Keywords: adjuncts, complements, negation, polarity, prepositions

Karen de Clercq/Liliane Haegeman

Department of Linguistics

Ghent University

Blandijnberg 2

B-9000 Ghent

Belgium

liliane.haegeman@ugent.be

karen.declerq@ugent.be

Terje Lohndal 
1401 Marie Mount Hall

University of Maryland

College Park, MD 20742

USA

terjeloh@gmail.com

\section{INTRODUCTION: AIM AND ORGANIZATION OF THE PAPER}

The starting point of this paper is a fairly widespread claim in the generative literature to the effect that sentence-medial adjunct PPs are unacceptable. Our paper makes two points. First, at the empirical level, we elaborate on Haegeman (2002), who showed that medial adjunct PPs are possible. We demonstrate on the basis of corpus data that sentence-medial adjunct PPs are not unacceptable and are attested. Our corpus data also reveal a sharp asymmetry between negative and non-negative adjunct PPs, which was noted by De Clercq (2010a,b) but was not thoroughly discussed there. The analysis of the corpus revealed the following pattern: Non-negative adjunct PPs such as at that time resist medial position and instead tend to be post-verbal. Negative adjunct PPs such as at no time appear medially rather than postverbally.

The second part of the paper looks at some theoretical implications of our findings for the syntax of negative PPs. We broaden the empirical domain and include negative complement PPs in the discussion. It is shown that when it comes to the licensing of question tags, English negative complement PPs, which are postverbal, pattern differently from postverbal negative adjunct PPs. Put informally: sentences with a postverbal negative adjunct PP pattern with negative sentences in taking a positive question tag, while sentences containing a postverbal negative argument PP pattern with affirmative sentences in taking a negative tag. To account for the observed adjunct-argument asymmetry in the licensing of 
question tags, we will propose that clauses are typed for polarity and we explore the hypothesis (Laka 1990, Progovac 1993, 1994, Moscati 2006, 2011, De Clercq 2011a,b, McCloskey 2011 etc.) that a polarity head in the left periphery of the clause is crucially involved in the licensing of sentential negation.

The paper is organized as follows: Section 2 considers the status of non-negative medial adjunct PPs. Section 3 examines the distribution of negative adjunct PPs. Section 4 elaborates our account of the licensing of sentential negation, which relies on a clause-typing mechanism established by a polarity head in the left periphery of the clause. Section 5 is a brief summary of the paper.

\section{MEDIAL POSITION FOR CIRCUMSTANTIAL PPS IN ENGLISH}

When realized by adverbs, English adjuncts are found in three positions: (i) initial (1a, 2a), (ii) medial (1b, 2b), (iii) postverbal (1c, 2d). (1) illustrates the patterns in a sentence with only a lexical verb; (2) illustrates the patterns in a sentence with an auxiliary and a lexical verb. The difference between the patterns in $(2 b)$ and $(2 c)$ is tangential to the discussion and we will group them under 'medial position'.

(1) a. Recently he left for London.

b. He recently left for London.

c. He left for London recently.

(2) a. Recently he has left for London.

b. He recently has left for London.

c. He has recently left for London.

d. He has left for London recently. 
With respect to adjuncts realized by PPs, the literature has generally focused on initial $(3,4 a)$ or postverbal $(3,4 c)$ PPs, with little or no discussion of medial PPs $(3,4 b)$ :

(3) a. At that time the actor lived in London.

b. The actor at that time lived in London.

c. The actor lived in London at that time.

(4) a. At that time the actor was living in London

b. The actor was at that time living in London.

c. The actor was living in London at that time.

In this section, we discuss these data more carefully based on literature surveys and corpus studies.

\subsection{Medial position adjunct PPs: the literature}

As pointed out by Haegeman (2002), there is a tendency in the generative tradition to consider medial adjunct PPs $(3 \mathrm{c}, 4 \mathrm{c})$ unacceptable in absolute terms, in contrast to medial adverbs. For instance, commenting on (5), Jackendoff (1977:73) says: 'First let us deal with the differences between AdvPs and PPs in V". The most salient difference is that AdvPs may appear preverbally as well as postverbally, whereas PPs may only be postverbal.'
a. Bill dropped the bananas $\{$ quickly $\}$
with a crash
b. Bill $\left\{\begin{array}{l}\text { quickly } \\ \text { *with a crash }\end{array}\right\}$ dropped the bananas.

(from Jackendoff 1977:73, (4.40)), 
This type of judgment is reiterated in the literature, we refer to Emonds (1976), who treats medial PPs such as those in (3b, 4b) as parentheticals, Nakajima (1991), Rizzi (1997:301), Frey and Pittner (1998:517, 1999:175), Pittner (2004:272), Cinque (2004:699-700), Haumann (2007), Belletti and Rizzi (2010) etc. Reproducing the judgment in (5), Cinque (1999:28) writes:

Circumstantial adverbials also differ from AdvPs proper in that they are typically realised (with the partial exception of manner adverbials) in prepositional form (for three hours, in the kitchen, with great zeal, for your love, in a rude manner, with a bicycle, etc..) or in bare NP form (the day after, tomorrow, this way, here etc.. [...]). Furthermore, possibly as a consequence of this, they cannot appear in any of the preVP positions open to AdvPs proper (except for the absolute initial position of "adverbs of setting", a topic-like position).

While we don't take issue with the actual judgments of specific examples, the authors' extrapolation that all medial PPs are ruled out does not correspond to the empirical data.

As a matter of fact, there is no agreement amongst authors that medial adjunct PPs are unacceptable. For instance, on the basis of the judgments in (6) McCawley (1998:207) does confirm the general tendency for adjunct PPs to resist medial position, but he also provides (7) (McCawley 1998:214, note 25), with acceptable medial adjunct PPs. He comments: 'I don't know of any neat way to distinguish between the P's in [6] and the ones in [7]'. (McCawley 1998:214, note 25).

(6) a. John was carefully/*with care slicing the bagels.

b. ?? We will for several hours be discussing linguistics. 
c. ?? Ed in Atlanta was struck by a truck.

(7) a. John has for many years been a Republican.

b. John has on many occasions voted for Republicans.

Focussing on journalistic prose, Haegeman (2002) shows that medial PPs are regularly attested. The following illustrate a medial adjunct PP in a finite clause without an auxiliary (8a), a finite clause with an auxiliary (8b), as well as a non-finite clause (8c):

(8) a. Burton moved in with Speke and the collaboration within two months produced a 200,000 word book, which sold 5,700 copies in its first year and was translated all over Europe. (Guardian, August 13, 2001, p. 8, col. 4)

b. The strength and charm of his narratives have in the past relied to a considerable extent on the first person presence of Lewis himself (Observer, July 22, 2001, Review, p. 3, col. 2)

c. It is fine, keep going, but then we have to after a day or two just leave this to the committee. (Guardian, August 20, 2003, p. 4, col. 6)

Several authors (Quirk 1985:492, 514, 521, Ernst 2002a:504, 2002b:194, Huddleston and Pullum 2002:780) signal that weight considerations play a part in restricting the availability of non-parenthetical medial PP adjuncts. For a discussion of a definition of weight in determining word order we refer to Ernst (2002b:194) and the references cited there.

\subsection{Medial position adjunct PPs are rare}

While the claim that medial PPs are categorically unacceptable is definitely incorrect, medial adjunct PPs are not as frequent as medial adverbs. Quirk et al. (1985) provide an overview of 
the distribution of a range of adverbial expressions in the various positions in a sample of the Survey of English Usage (cf. their description 1985:489). Tables 1 and 2 are based on their table 8.23 and summarise the percentages of adjunct PPs and adjunct adverbs in initial, medial and postverbal position. While Quirk et al. distinguish a number of medial and postverbal positions, our tables simplify their table 8.23 in that we have grouped their distinct medial positions into one position and we have also collapsed their postverbal positions into one. Medial PPs are systematically outnumbered by postverbal PPs, both in writing and in speech. For adverbs, the opposite relation holds: medial adverbs are slightly more frequent than postverbal ones. That medial PPs are rare is also occasionally signalled in pedagogically oriented grammars such as, for instance the Collins COBUILD grammar (Sinclair 1990:283) and Lambotte (1998).

Table 1: Distribution of PPs in the Survey of English Usage (Quirk et al.:1985: 501)

\begin{tabular}{|l|l|l|l|l|}
\hline & $\%$ Initial & $\%$ Medial & $\%$ End & Total number \\
\hline Spoken & 6 & 1 & 93 & 2063 \\
\hline Written & 12 & 3 & 85 & 2351 \\
\hline Average & 9,5 & 2,5 & 88 & $4456^{1}$ \\
\hline
\end{tabular}

Table 2: Distribution of adverbs in the Survey of English Usage (Quirk et al.:1985: 501)

\begin{tabular}{|l|l|l|l|l|}
\hline & \% Initial & $\%$ Medial & $\%$ End & Total number \\
\hline Spoken & 17,5 & 44,5 & 38 & 608 \\
\hline Written & 15 & 50 & 35 & 462 \\
\hline Average & 16 & 47 & 37 & $1063^{2}$ \\
\hline
\end{tabular}


In order to assess the status of medial adjunct PPs in present-day English, we undertook a pilot search of the American COCA corpus and the British BNC corpus at http://corpus.byu.edu/coca/, in which we examined the distribution of the following temporal adjunct PPs: on three occasions, on those occasions, at one time, at a time, at some time, at this time, at that time, on many occasions and also of the manner adjunct in this way. For adjunct PPs occurring at a very high frequency (at one time, at a time, at some time, at this time, at that time, on many occasions, in this way), we based our study on a sample of the first 100 entries. We present our results in tables 3 and 4. Obviously, these figures in no way represent the full and final picture of the distribution of adjunct PPs, nor does our paper offer a statistical analysis of such data, but our findings suffice to show (i) that sentence-medial adjunct PPs are certainly attested, and (ii) that, fully in line with the literature, such medial adjunct PPs are outnumbered by postverbal adjunct PPs. In section 3 we will see, however, that for a well-defined class of PP adjuncts, medial position is not just an option but is actually strongly preferred over postverbal position.

Table 3: Pilot study: distribution of PPs in medial position: COCA-sample

\begin{tabular}{|l|l|l|l|l|l|}
\hline PP & Total & Initial & Medial & Postverbal & Not \\
\hline On three & 86 & 18 & 2 & relevant \\
\hline On those & 95 & 49 & 1 & 63 & 3 \\
\hline At one time & 100 & 27 & & 42 & 3 \\
\hline At a time & 100 & 9 & 13 & 36 & 24 \\
\hline At some time & 100 & 13 & 0 & 42 & $49^{3}$ \\
\hline
\end{tabular}




\begin{tabular}{|l|l|l|l|l|l|}
\hline At this time & 100 & 24 & 6 & 67 & 3 \\
\hline At that time & 100 & 35 & 10 & 54 & 1 \\
\hline On many & 100 & 28 & 5 & 64 & 3 \\
\hline occasions & & & & & \\
\hline In this way & 100 & 52 & 3 & 39 & 6 \\
\hline
\end{tabular}

Table 4: Pilot study: distribution of PPs in medial position: BNC-sample

\begin{tabular}{|l|l|l|l|l|l|}
\hline PP & Total & Initial & Medial & Postverbal & Not \\
\hline On three & 63 & 21 & 2 & 35 & 5 \\
\hline $\begin{array}{l}\text { On those } \\
\text { occasions }\end{array}$ & 29 & 8 & 0 & 20 & 1 \\
\hline At a time & 100 & 16 & 2 & 46 & 36 \\
\hline At one time & 100 & 37 & 28 & 24 & 11 \\
\hline At some time & 100 & 12 & 17 & 70 & 1 \\
\hline At this time & 100 & 24 & 6 & 68 & 2 \\
\hline At that time & 100 & 27 & 14 & 59 & 0 \\
\hline On many & 100 & 23 & 3 & 72 & 2 \\
\hline $\begin{array}{l}\text { occasions } \\
\text { In this way }\end{array}$ & 100 & 26 & 2 & & 2 \\
\hline
\end{tabular}




\section{SENTENTIAL NEGATION AND ADJUNCT PPS}

\subsection{Sentential negation in English}

In English, negation can be expressed in a number of different ways, the most common of which are illustrated in (9). For recent analyses and a survey of the literature we refer to Zeijlstra (2004), Christensen (2005, 2008), Tubau (2008) and Moscati (2006, 2011).

(9) a. The police did not talk to any witnesses.

b. $\quad$ No one talked to the police about any crime.

c. The police associated no one with any of these crimes.

d. The police talked to no one about any of these crimes.

e. The police never talked to any witnesses about the crime.

f. Never had the police talked to any witnesses.

The canonical marker of negation is the particle not (or its contracted form $n^{\prime} t$ ) adjacent to the finite auxiliary. Alternatively, an argument of the verb is realized as a negative nominal constituent, such as no one in (9b) or (9c), or as a PP containing a negative nominal as in (9d), which also conveys negation (but see section 4 for discussion). Finally, and most relevant for our purposes, in (9e) and (9f) a negative adjunct expresses sentential negation. In (9e) the adverb never is medial and in (9f) it is initial, triggering subject-auxiliary inversion (henceforth SAI) (see Rudanko 1980, Haegeman 2000, Sobin 2003).

Negative adjuncts with sentential scope can also be realized as PPs. In (10a) the negative quantifier $n o^{4}$ contained inside the initial temporal PP at no time has sentential scope: witness the fact that it triggers $\mathrm{SAI}^{5}$ and licenses the negative polarity item any in the complement of the verb. The negative PP differs from its non-negative counterpart at that time, which does not, and cannot, trigger SAI (11). 
(10) a. At no time had the police talked to any witnesses.

b. *At no time the police had talked to any witnesses.

(11) a. At that time the police had interviewed the witnesses.

b. *At that time had the police interviewed the witnesses.

Like negative adverbs, negative adjunct PPs with sentential scope can appear in sentencemedial position (12). The availability of the polarity item any in (12a) confirms that at no time has sentential scope. Though we will mainly focus on temporal PPs like (12a), other medial adjunct PPs can also express sentential negation (12b).

(12) a. The police had at no time talked to any of the witnesses.

b. The FQ at no level forms a constituent with the DP it modifies. (Will Harwood, Handout GIST, 13.01.2011)

In relation to the discussion in section 2 , the data in (12) obviously also challenge claims according to which medial adjunct PPs are categorically unacceptable. We go into these patterns in more detail here.

\subsection{Negative adjunct PPs and the expression of sentential negation}

Sentences with preposed negative constituents such as the pair in $(13 a, b)$ have been discussed extensively (see, among others, Rudanko (1980), Haegeman (2002), Sobin (2003), Radford (2004), Haumann (2007) and the references cited there). In (13a), without SAI, the negative quantifier no contained in the PP in no clothes encodes constituent negation ('without 
clothes') and does not take sentential scope; in (13b), with SAI, the PP-internal negative quantifier has sentential scope ('there are no clothes such that...').

(13) a. In no clothes Mary looks attractive.
b. In no clothes does Mary look attractive.

Less attention has been paid to the distribution and interpretation of postverbal negative PPs. We briefly go over some discussions in the literature.

Tottie (1983) studies the alternation between S[ynthetic] negation (he said nothing) vs. A[nalytic] negation (he did not say anything) in American English, using both informants' questionnaires and corpus material. However, her data do not include many relevant examples of PPs. Summarizing her conclusions on the basis of the informants' questionnaires she writes (1983:52):

An examination of the actual sentences from the sample reveals that those sentences that had S[ynthetic] negation in PrepPhrases were to a large extent fairly fixed collocations. Cf. [14], all be-sentences with PrepPhrases functioning as adverbials:

[14] a. In any case it is by no means clear that formally structured organs of participation are what is called for at all.

b. Mr Balaguer's troubles are by no means over. B 05

c. It is by no stretch of the imagination a happy choice. B 22 .

Observe that in the three examples in (14), the medial negative adjunct PP is not set off prosodically. Indeed, in spite of its relative weight, even the PP by no stretch of the 
imagination occupies medial position in (14c). Inserting commas in (14c) would entail that the negative PP cannot scope over the clause (14d) and would render the sentence unacceptable.

(14) d. *It is, by no stretch of the imagination, a happy choice.

In their discussion of negative markers in English, Quirk et al. (1985:783) systematically compare a positive sentence with its negative alternative. Their example set (15) is of interest in the light of our discussion. While in the positive (15a) the adverb somehow is in postverbal position, the negative adjunct PP is placed medially in (15d). Quirk et al. do not comment on this shift in position.

(15) a. They'll finish it somehow.

b. They won't in any way finish it.

c. They won't finish it at all.

d. They will in no way finish it. (Quirk et al 1985:783, (8))

Huddleston and Pullum (2002) distinguish 'verbal' negation, expressed by medial not or n't associated with an auxiliary, as in (9a) or $(15 b, c)$, from 'non-verbal' negation, expressed by means of a negative constituent such as a negative quantifier (no, nothing, no one, etc.) or a negative adverb (never, no longer, no more). Relevantly, they provide (16a) as an instance of a non-verbal sentential negation (2002: 789, their [5ii]). In this example negation is encoded in a postverbal adjunct PP. Following Klima (1964), McCawley (1998), Horn (1989), Haegeman (2000), De Clercq (2010a), etc. the standard diagnostics to detect negativity (16be) show that the postverbal negative constituent in (16a) can take sentential scope. ${ }^{6}$ 
(16) a. We were friends at no time.

b. We were friends at no time, not even when we were at school. (Huddleston and Pullum 2002:789, their [10ia])

c. We were friends at no time, and neither were our brothers.

d. We were friends at no time, were we?

e. At no time were we friends.

Along the same lines, Haumann (2007:230) provides (17a), in which postverbal on no account negates the sentence and Kato (2002) presents (17b) as an instance of sentential negation expressed by a postverbal negative PP (but see the discussion around (22) below):

(17) a. She will go there on no account, not even with John. (Haumann 2007: her (130b))

b. He will visit there on no account. (Kato 2002:67 (14a))

However, native speakers often consider sentences with postverbal negative adjunct PPs as less than perfect. And indeed, while they present (16a) without comments, Huddleston and Pullum (2002:814) themselves signal that in fact postverbal negative PPs lead to a lower acceptability. They illustrate this point by means of the (weak) contrasts in (18) and (19): the examples in (18) with a negative adjunct PP in postverbal position, are more marked than the corresponding sentences in (19) which contain a combination of the negative marker not with a postverbal adjunct PP containing an NPI:

(18) a. ? I am satisfied with the proposal you have put to me in no way. 
b. ?As far as I can recall, I have purchased food at the drive-through window of a fast -food restaurant on no street in this city.

(19) a. I am not satisfied with the proposal you have put to me in any way.

(Huddleston and Pullum (2002:814, [24i])

b. As far as I can recall, I have not purchased food at the drive-through window of a fast-food restaurant on any street in this city.

(Huddleston and Pullum (2002:814, [24ii])

As shown in the extract below, the authors account for the contrasts above in terms of processing load, rather than in terms of grammaticality:

In principle, non-verbal negators marking clausal negation can appear in any position in the clause. However, as the position gets further from the beginning of the clause and/or more deeply embedded, the acceptability of the construction decreases, simply because more and more of the clause is available to be misinterpreted as a positive before the negator is finally encountered at a late stage in the processing of the sentence. (Huddleston and Pullum 2002:814)

Though Huddleston and Pullum do not pursue this point themselves, their account of the contrasts between (18) and (19) leads to the correct prediction that medial position will be preferred for the negative adjunct PP: (18a) and (18b) are definitely improved with the negative PP in medial position. Observe that even for the slightly longer PP on no street in this city in (20b), considerations of weight do not lead to a degradation.

(20) a. I am in no way satisfied with the proposal you have put to me. 
b. As far as I can recall, I have on no street in this city purchased food at the drive-through window of a fast -food restaurant. ${ }^{7}$

De Clercq (2010 a, b) reports the judgments in (21) - (24). (21) shows that while the nonnegative PP at that time is accepted both in medial (21a) and postverbal (21b) position, its negative analogue remains acceptable in medial position (21c) but postverbal position (21d) is rejected. In contrast with the judgment reported by Kato (17b), postverbal on no account in (22b) is also considered unacceptable by De Clercq's informants. (23) and (24) provide additional judgments along the same lines.

(21) a. The police had at that time interviewed the witnesses.

b. The police had interviewed the witnesses at that time.

c The police had at no time talked to the witnesses.

d. $\quad ?^{*}$ The police had talked to the witnesses at no time.

(22) a. You should on no account move to Paris.

b. $\quad$ ?*You should move to Paris on no account.

(23) a. She should at no time reveal the secret.

b. $\quad$ ?*She should reveal the secret at no time.

(24) a. They would under no circumstances reveal the problem.

b. *They would reveal the problem under no circumstances.

A fully acceptable alternative to a sentence with a postverbal negative adjunct PP is one in which sentential negation is expressed by the canonical marker of sentential negation $n o t / n ' t$ and in which a negative polarity item (NPI) any replaces the negative quantifier no in the postverbal PP. The contrast between the perfect (25) and the contrasts in acceptability 
observed for degraded (22b, 23b, 24b) suggests that it is the negative component of the postverbal PPs that causes the degradation.

(25) a. She should not reveal the secret at any time. (De Clercq 2010b)

b. You should not move to Paris on any account.

c. They would not reveal the problem under any circumstances.

\subsection{The distribution of negative PP adjuncts}

In section 2.2, we saw that as far as non-negative adjunct PPs are concerned, postverbal PPs outnumber medial PPs in the English corpora considered. To assess the distribution of their negative counterparts we examined the distribution of the negative adjunct PPs at no time, on no account, by no stretch of the imagination, on no occasion, in no event, at no other $N$ and in no way (cf. Quirk et al's (20) above). Our pilot study reveals an asymmetry between negative PPs and non-negative PPs. Medial non-negative PPs are less frequently attested than postverbal non-negative PPs. Medial negative PPs are far more frequent than postverbal negative PPs, which are in fact very rare indeed. These findings offer further support for Haegeman's claim (2002) that medial adjunct PPs are not categorically excluded. On the other hand, while non-negative adjunct PPs are easily available in postverbal position, postverbal negative PPs with sentential scope, while available, are the marked option.

Tables 5 and 6 summarize the results of our searches for the negative PPs at no time, on no account, by no stretch of the imagination, on no occasion, in no event, at no other $N$ (cf. $(26 \mathrm{e}, \mathrm{f}, \mathrm{g})$ and in no way.

Table 5: Distribution of negative adjunct PPs in COCA 


\begin{tabular}{|l|l|l|l|l|l|}
\hline PP & Total & Initial & Medial & Postverbal & Not \\
\hline At no time & & (SAI) & & & relevant \\
\hline On no account & 21 & 21 & 0 & 0 & 0 \\
\hline By no stretch of the & 10 & 6 & 4 & 0 & 0 \\
\hline imagination & & & 4 & 0 & 0 \\
\hline On no occasion & 3 & 2 & 0 & 0 & 1 \\
\hline In no event & 9 & 9 & 0 & 0 & 0 \\
\hline At no other $N$ & 34 & 23 & 0 & 3 & 8 \\
\hline In no way & 100 & 14 & 84 & 2 & 0 \\
\hline
\end{tabular}

Table 6: Distribution of negative adjunct PPs in BNC

\begin{tabular}{|l|l|l|l|l|l|}
\hline PP & Total & Initial & Medial & Postverbal & Not \\
& & (SAI) & & & relevant \\
\hline At no time & 100 & 86 & 13 & 0 & 1 \\
\hline On no account & 84 & 67 & 17 & 0 & 0 \\
\hline By no stretch of the & 14 & 9 & 5 & 0 & 0 \\
\hline imagination & & & & & \\
\hline On no occasion & 3 & 2 & 1 & 0 & 0 \\
\hline In no event & 0 & 0 & 0 & 0 & 0 \\
\hline At no other $N$ & 9 & 5 & 0 & 3 & 1 \\
\hline In no way & 100 & 8 & 90 & 0 & 2 \\
\hline
\end{tabular}

The lower frequency of postverbal negative adjunct PPs sets them off sharply from postverbal non-negative adjunct PPs, which, as shown in Tables 3 and 4, are well-attested. To complete 
the picture, Tables 7 and 8 provide the relevant figures for medial and postverbal position of the corresponding adjunct PPs containing an NPI: at any time, under any circumstances, on any account and on any occasion. For at any time and in any way, we have again used a reduced sample of 100 examples. As was the case for the non-negative PPs discussed in section 2, postverbal position is more easily available.

Table 7: distribution of NPIs: medial and postverbal position: COCA

\begin{tabular}{|l|l|l|l|l|l|}
\hline PP & Total & Initial & Medial & Postverbal & Not relevant \\
\hline On any occasion & 12 & 0 & 0 & 7 & 5 \\
\hline On any account & 8 & 0 & 4 & 3 & 1 \\
\hline By any stretch of the & 100 & 4 & 8 & 60 & 28 \\
\hline At any time & 100 & 9 & 1 & 86 & 4 \\
\hline In any way & 100 & 0 & 30 & 68 & 2 \\
\hline
\end{tabular}

Table 8: distribution of NPIs: medial and postverbal position, BNC

\begin{tabular}{|c|c|c|c|c|c|}
\hline $\mathrm{PP}$ & Total & Initial & Medial & Postverbal & Not relevant \\
\hline On any occasion & 11 & 3 & 4 & 1 & 3 \\
\hline On any account & 18 & 0 & 12 & 5 & 1 \\
\hline $\begin{array}{l}\text { By any stretch of } \\
\text { the imagination }\end{array}$ & 21 & 0 & 6 & 10 & 5 \\
\hline At any time & 100 & 14 & 11 & 71 & 4 \\
\hline In any way & 100 & 0 & 45 & 53 & 2 \\
\hline
\end{tabular}

Some of the (rare) postverbal occurrences of negative PPs are illustrated in (26). 
(26) a. I judge you in no way, Eunice. (COCA 2008: Fiction, Harriet Isabella)

b. He really likes and appreciates a wide range of people who resemble him in no way whatsoever. ${ }^{9}$ (COCA 2001: news, Washington Post)

c. The fall also produced a strong smell of methylated spirits - something repeated at no other meteorite fall. (COCA 2006: Mag, astronomy)

d. For a kind of light and a sweep of possibility that comes at no other time. (COCA 1979, MAG, Skiing)

e. It showed a flash of strategic prescience that he displayed at no other moment in his military career. (BNC: CLXW: non-ac-humanities-arts)

f. Such as has been available at no other period of British history (BNC EEW9, W-non acad, SocScience)

g. The success of this unique element, which exists at no other German University (COCA 1990, Acad, Armed Forces).

In preparation for the next section we need to add one ingredient to the discussion, which we have not touched upon so far: whereas negative adjunct PPs resist postverbal position, the canonical position of negative complement PPs is postverbal (27a). Indeed there is no medial position available for negative complement PPs (27b). However, the postverbal position of the negative complement PP is felt to be a marked option in comparison to encoding negation medially by means of the canonical marker of negation $n$ 't/not, where the corresponding postverbal PP contains an NPI, as in (27c):

(27) a. Mary has talked to no one.

b. *Mary has to no one talked. 
c. Mary hasn't/not talked to anyone.

\section{WAYS OF EXPRESSING SENTENTIAL NEGATION}

In this section we outline an account for the asymmetry in the distribution of negative adjunct PPs, and in particular for their strong preference for medial position. Our account explores proposals in De Clercq (2010a, 2011a,b). On one of the two derivations of postverbal adjunct PPs presented below, the processing complexity which Huddleston and Pullum (2002) associate with the postverbal negative adjunct PPs can be argued to have a syntactic basis. In this paper we do not discuss how to account for the distribution of non-negative adjunct PPs.

\subsection{Question tags and negative clause-typing}

Ever since Klima (1964) reversal tags or question tags ${ }^{10}$ as illustrated in (28) have been used as a diagnostic to determine whether a sentence is affirmative or negative (McCawley 1998, Horn 1989):

(28) a. John is working on a $\mathrm{PhD}$, isn't he?

b. John isn't working on a $\mathrm{PhD}$, is he?

Standardly, it is proposed that a negative question tag identifies an affirmative sentence (28a) and that a positive question tag identifies a negative sentence. Let us adopt the tag test as a diagnostic to determine the polarity of the clause, focusing on sentences containing a negative PP. Informally, we will say that clauses are typed for polarity as either negative or positive. Needless to say, clause-typing for polarity ([+/- NEGATIVE]) is orthogonal to clause-typing for interrogative/declarative $([+/-\mathrm{WH}])$ since the value [+/- NEGATIVE] may combine with the value $[+/-\mathrm{WH}]$. Along these lines, a sentence negated by medial not/n't is negative, and so is a 
sentence which contains medial never (29a). A sentence containing a medial negative adjunct PPs is compatible with a positive question tag (29b) and hence is also 'negative' in the intended sense.

(29) a. Mary has never talked to anyone, has she?

b. She had at no point talked to anyone, had she?

As discussed above, postverbal negative adjunct PPs are rare, but to the extent that they are accepted, such sentences are only compatible with positive tags. (30a) is from Huddleston and Pullum (2002), (30b) is based on Huddleston and Pullum's [24i]. We conclude that postverbal negative adjunct PPs also type the clause as negative.

(30) a. We were friends at no time, were we?

b. As far as I can recall, we have purchased food at the drive-through window of a fast -food restaurant on no street in this city, have we/*haven't we.

(based on Huddleston and Pullum (2002:814, [24ii])

When it comes to sentences containing negative complement PPs though, the pattern of question tags is reversed for our informants: as can be seen in (31), while sentence-medial not induces a positive tag, the sentence with the postverbal negative complement PP to no one is compatible with a negative $\operatorname{tag}^{11}$ (see also Horn 1989:185, (ixb) citing Ross 1973 for a similar example with a negative nominal complement).

(31) a. Mary has talked to no one, *has she/ hasn't she/?

b. Mary hasn't/not talked to anyone, has she/*hasn't she? 
We conclude then that there is an argument-adjunct asymmetry: while postverbal negative adjunct PPs may be rare, to the extent that they are possible they type the clause as negative. On the other hand, we can see that postverbal negative complements do not type the clause as negative, since they are not compatible with a positive question tag.

\subsection{Clause-typing and sentential negation}

Our hypothesis is that clauses are typed for polarity: they are either positive or negative. Polarity determines the choice of question tag. In line with the cartographic approach (Rizzi 1997, Moscati 2006), we will assume that polarity typing is syntactically encoded on a head in the C domain such as Laka's (1990) $\Sigma$ P, or Progovac's $(1993,1994)$ PolP. We propose that in the case of negative sentences, this head must establish a local checking relation with a negative constituent. From the distribution of the tags, we conclude that the medial negative marker not and the medial adverb never are able to license the clause-typing negative head in the C-domain and that postverbal negative PP complements cannot do so.

(32) Mary hasn't talked to anyone, has she?
b. Mary has never talked to anyone, has she?
c. *Mary has talked to no one, has she?

We interpret the contrast in (32) as deriving from locality conditions on clause-typing. Putting this first at an intuitive level, the negation in (32c) is 'too far' from the $\mathrm{C}$ domain to be able to type the clause as negative and hence to license the positive tag. Various implementations can be envisaged to capture these locality restrictions. In terms of Phase theory (Chomsky 2001, 2008), for instance, one might say that being contained within a lower phase (vP), the 
postverbal negative complement PPs cannot establish the required licensing relation with the relevant head in the $\mathrm{C}$-domain.

To make this proposal more precise, let us propose that the polarity related head in the $\mathrm{C}$ domain contains an unvalued feature, [POL:_], which has to be assigned a value through a local checking relation. In (32a) and in (32b), with the medial negative markers not and never, the feature [POL:_] in the C-domain can be valued through an AGREE relation with the interpretable negative feature on never. ${ }^{12}$ If the C-polarity head is typed as negative, then the clause will be compatible with a positive tag.

In (32c), on the other hand, the negative quantifier no one in the VP-internal argument PP is contained in the vP Phase and hence it is too low to be able to value the clausal polar head by an AGREE relation. We assume that in the absence of a negatively valued checker, the polarity feature of the clause is typed as positive by default and will hence not be compatible with the positive reversal tag.

$$
\begin{aligned}
& \text { a. } \quad\left[\mathrm{CP} \quad\left[\mathrm{C} \text { POL: NEG] [TP Mary has not }{ }_{[\mathrm{NEG}]}\left[{ }_{\mathrm{vP}} \text { talked to anyone }\right]\right]\right. \\
& \text { b. } \quad\left[\mathrm { CP } \quad \left[\mathrm{C} \text { POL: NEG] [TP Mary has never }{ }_{[\mathrm{NEG}}[\mathrm{vP} \text { talked to anyone] }]\right.\right. \\
& \text { c. }\left[\mathrm{CP} \quad[\mathrm{CPOL}]\left[\text { [TP Mary has }\left[\mathrm{vP}_{\mathrm{vP}} \text { talked to no one }{ }_{[\mathrm{NEG}]}\right]\right]\right]
\end{aligned}
$$

A final remark is in order here. Though it does not lead to a positive tag, $(31 \mathrm{a} / 33 \mathrm{c})$ is still felt to be a 'negative' sentence due to the presence of the negative DP. For instance, like (32a) and (32b), (32c) will combine with a neither tag rather than with a so tag. ${ }^{13}$ Klima (1964) considers neither tags also to be a diagnostic for negativity (see also (16c) above):

(34) a. Mary has not talked to anyone, and neither/*so has Jane.

b. Mary has never talked to anyone, and neither/*so has Jane. 
c. Mary has talked to no one, and neither/*so has Jane.

As discussed already by McCawley (1998:604-612), the reversal tag-diagnostic which we used previously and the neither/so tag give different results. It is not clear to us at this point how to capture this in terms of our discussion. De Clercq (2011b) proposes that in examples such as (34c) the negation encoded in no one within the complement of $\mathrm{V}$ takes scope by virtue of its quantificational properties, in the same way that, for instance, the universal quantifier encoded in everyone can scope over the clause in (35). The precise implementation of this proposal would lead us too far and it also depends on the assumptions to the syntactic encoding of scope and we refer to De Clercq (2011b) for one proposal. Crucial for us is that, syntactically, the postverbal vP-internal argument cannot establish a local checking relation with the polarity feature, which by hypothesis is in the $\mathrm{C}$ domain: polarity checking is different from the operation that determines the scope of the quantifier in (35).

(35) Mary has talked to everyone.

We tentatively assume that the neither tag is sensitive to the scopal/quantificational properties of the negative quantifier in a way that the reversal tags are not.

\subsection{Clause-typing and adjunct PPs}

Let us now return to the distribution of negative adjunct PPs. We have seen that the preferred position for such PPs is medial, rather than postverbal. A sentence with a medial negative adjunct PPs is compatible with a positive reversal tag (36a), entailing that the negative PP must be able to type the clause. Pursuing our analysis, we will assume that, like the marker of negation not and like the medial negative adverb never, the medial negative adjunct PP is in a sufficiently local relation to the C-domain to value the polarity feature. We conclude from this 
that such PPs must not be contained within the vP phase. If they were, then we would not expect them to pattern with medial not and never. Depending on one's assumptions about functional structure, the negative PP might be vP adjoined (36b) or it might be taken to be the specifier of a medial functional projection (36c), which we label FP. ${ }^{14}$

(36) a. She had at no point talked to anyone, had she?

b. [CP [C POL:NEG] [TP She had [ ${ }_{\mathrm{vP}}$ at no ${ }_{[\mathrm{NEG}]}$ time $\left[{ }_{\mathrm{vP}}\right.$ talked to anyone $\left.\left.\left.]\right]\right]\right]$

c. [CP [C POL:NEG] [TP She had [FP at no ${ }_{[\mathrm{NEG}}$ time $\left[{ }_{\mathrm{vP}}\right.$ talked to anyone]]]

Postverbal negative adjunct PPs are marginal, but to the extent that they are available they were shown to be compatible with positive tags (16d), suggesting that they too type the clause. The analysis of such examples depends on one's general assumptions about the syntax of postverbal PPs (see Cinque 2004, Belletti and Rizzi 2010, for overview of some options). If right adjunction is admitted in the theory (cf. Ernst 2002a, 2002b), at no time in (37a) might be right-adjoined to $\mathrm{vP}$. Hierarchically speaking, though postverbal, the PP in (37b) is outside vP and remains within the local checking domain of the polarity head in C. Given that in terms of hierarchical relations, the relation between $\mathrm{C}$ and the postverbal adjunct in $(37 \mathrm{~b})$ is identical to that between $\mathrm{C}$ and the medial adjunct $\mathrm{PP}$ in $(35 \mathrm{~b}, \mathrm{c})$, this approach does not offer any insight into the perceived degradation of negative adjunct PPs in postverbal position.

(37) a. She had talked to them at no time, had she?

b. [CP [C POL:NEG] [TP she had $\left[{ }_{\mathrm{vP}}\left[\mathrm{vP}\right.\right.$ talked to them] at no ${ }_{[\mathrm{NEG}]}$ time $\left.]\right]$

On an anti-symmetric/cartographic view in which right adjunction is not available (Cinque 2004), one might propose that the negative PP occupies the specifier position of a functional 
projection, FP (as in (37c)), and that its postverbal position is derived by leftward movement of the vP to a higher position. The movement could arguably be triggered by the need for the negative PP to receive focal stress (cf. Jayaseelan 2008, 2010).

c. $\quad[\mathrm{CP} \quad[\mathrm{C}$ POL:NEG $][$ TP she had

[ [ ${ }_{\mathrm{vP}}$ talked to them] [FP at no ${ }_{[\mathrm{NEG}]}$ time [vP talked to them] $\left.]\right]$

Assuming that the projection hosting the PP and that hosting the fronted $\mathrm{vP}$ do not themselves constitute phases, the polarity head in $\mathrm{C}$ can continue to establish a local checking relation with the postverbal negative PP in (37c). On a more speculative note, we add here that the representation in $(37 \mathrm{c})$ may contribute to explaining the observation that the postverbal position of the negative $\mathrm{PP}$ (37a) is degraded: the fronting of the vP to a position ccommanding the negative PP might be argued to create a weak intervention effect for the relation between $\mathrm{C}$ and the negative $\mathrm{PP}$.

A correct prediction of our account is that a negative DP in the canonical subject position always types the clause as negative: (38a) is only compatible with a positive tag. This is so because the negative feature on no one is in a local relation with the polarity feature in $\mathrm{C}:$

(38) a. No one talked to the police about any crime, did they?

b. [CP [C POL:NEG [TP No one ${ }_{[\mathrm{NEG}}$ talked to the police about any crime.]] The proposal developed here, elaborating on De Clercq's work, also has further implications for the representation of clause structure and in particular for the demarcation of phases. Passive sentences with a postverbal negative by phrase take a negative question tag (39). In 
terms of our account this entails that, as is the case for postverbal arguments, the negative component no one cannot value the polarity feature in the C-domain. This implies that, unlike postverbal adjuncts, the by phrase must be contained within a phase. We do not pursue this issue here as it hinges, among other things, on the analysis of passives (see Collins 2005 for a recent analysis).

(39) The book was adapted by no one, wasn't it?

\section{CONCLUSION}

This paper first challenges the empirical claim sometimes made in the generative literature that medial adjunct PPs are ungrammatical in English. On the basis of a corpus study we show that (i) medial non-negative adjunct PPs are attested both in American and in British English, though with low frequency, and (ii) that medial negative adjunct PPs strongly outnumber postverbal negative adjunct PPs. We conclude that any empirical generalisations to the effect that medial adjunct PPs are always unacceptable are ill-founded.

In the second part of the paper we explore the syntax of sentential negation. The distribution of question tags reveals that among negative PPs, postverbal argument PPs pattern differently from postverbal adjunct PPs. We account for this argument/adjunct asymmetry in terms of a clause-typing account of sentential polarity, which crucially postulates a licensing relation between a polarity head in the C-domain and a constituent which encodes negation, and we pursue some of the consequences of this account.

\section{ACKNOWLEDGMENTS}


Karen De Clercq and Liliane Haegeman's research is part of the FWO project 2009-

Odysseus-Haegeman-G091409. We thank Rachel Nye, Geoff Pullum and Barbara Ürögdi for help with English judgments. Part of this material was presented at the LAGB 2011 meeting in Manchester. We thank David Adger, Doug Arnold, Joan Maling and Gary Thoms for their comments. We thank three anonymous reviewers for the Nordic Journal of Linguistics, Rachel Nye and Neil Smith for comments on an earlier version of this paper. Needless to say all the usual disclaimers hold.

\section{NOTES}

1 The discrepancy between the figures for spoken and written material and the totals are not accounted for in Quirk et al. (1985).

$2 \quad$ Again Quirk et al. do not account for the discrepancy in the totals.

Note that we only report on open class adverbs. We don't include in the count closed class adverb such as then, just etc.

3 We have discounted occurrences of at a time followed by a temporal clause (at a time when ...) which are final for weight reasons and for which medial position is unavailable.

$4 \quad$ The use of the term 'negative quantifier' to refer to no is a simplification. We do not wish to commit ourselves here to its exact nature. See Haegeman and Lohndal (2010) for discussion of the nature of such negative items.

5 An anonymous reviewer claims that (10b) is acceptable as an example of constituent negation. We disagree, if at no time is intended to encode constituent negation and hence lacks sentential scope the example will be ungrammatical because the NPI any in the complement of the verb is not licensed. Our informants judge (10b) as unacceptable.

6 There is some speaker variation in the acceptance rate of (16a) and also with respect to (18) and (30) below, but overall our informants' judgements follow the tendencies reported in Huddleston and Pullum (2002).

$7 \quad$ Thanks to Geoff Pullum for generous help with these data. 
8

On a very anecdotal level, a Google search of the string were friends at no time yielded exactly one relevant hit, namely a citation of Huddleston and Pullum's very own example (http://languagelog.ldc.upenn.edu/nll/?p=2689).

Neil Smith (p.c) and Barbara Ürögdi (p.c) point out that focal stress makes postverbal PPs more acceptable.

For discussion of focal stress see also the discussion of text example (36) in section 4.

For the use of question tags see also the discussion in Horn (1989: 184-189). Observe that there are two kind of tags: 1) question tags or reversal tags (McCawley 1988) and 2) reduplicative tags or same-way tags (Swan 2005). Question tags reverse the polarity of the matrix clause and usually check for information. Reduplicative tags reduplicate the polarity of the matrix clause and signal the speaker's conclusion by inference, or his sarcastic suspicion (Quirk et al. 1985). The latter are only possible with affirmative sentences. Sentences with reduplicative tags can typically be preceded by $O h$ or so (Quirk et al. 1985: 810-813). It is important to keep the tags apart. In the literature, confusing these tags has led to the wrong conclusions about which polarity certain quantifiers give rise to (De Clercq 2011b: footnote 2). In our paper, we only consider question tags. An anonymous reviewer points out that neither the positive or the negative tag is in fact fully grammatical with the 'negative' argument PP. This may well be true but the fact is that our informants consistently prefer the negative tag over the positive one. Nevertheless, speaker variation should indeed be taken into account. Experimental research would be useful to get a clearer picture on speakers' preferences for certain tags. Crucial for the present analysis is the fact 1) that there is a clear distinction between negative PP-adjuncts that always give rise to positive question tags and negative PPcomplements that preferentially lead to negative question tags and 2) that negative question tags are for many speakers definitely an option with negative objects (not only PP-objects) unlike with negative subjects, as also reported in McCawley (1998: 507):

(i) Fred talked to no one, didn`t he? (McCawley 1998: 507)

We leave open the possibility that TP also contains a polarity related projection such as NegP or PolP. Cf. Haegeman and Zanuttini (1991, 1996), Haegeman (1995), Smith and Cormack (1998), Christensen (2005, 2008), Moscati (2006, 2011, Tubau (2008) and Haegeman and Lohndal (2010) for discussion of the representation of sentential negation 
14 We label this projection FP, leaving it intentionally open what its specific nature is. One option is to identify FP with NegP, bearing in mind that NegP contributes to but is not the sole expression of sentential negation, which is encoded at the CP level (see also note 12). One might also label the projection PolP and assume then that the negative PP will determine a negative value for the Pol head.

One important question that remains to be clarified before the identify of FP can be established is whether there is a unique position in the English middlefield that hosts negative PPs and negatively quantified adverbs (never) or whether more than one such projection should be envisaged (see Zanuttini 1997 on Italian and Cinque 1999: chapter 4 for the hypothesis that each adverbial projection may be associated with a negative layer.) Relevant for this issue is the fact that middlefield constituents that encode negation do not all pattern alike. For instance, though both not and never occur in the middlefield, the former requires do insertion and the latter does not. Similar contrasts are observed for French where pas ('not') patterns differently from plus ('no more'), as shown in Belletti (1990). For negative constituents in Italian see esp. Zanuttini (1997). 


\section{REFERENCES}

Belletti, Adriana. 1990. Generalised verb movement. Turin: Rosenberg and Sellier.

Belletti, Adriana \& Luigi Rizzi. 2010. Moving verbal chunks. Ms. University of Siena.

BNC. The British National Corpus Online Service. Mark Davies. November-December 2010. http://corpus.byu.edu/bnc/

Chomsky, Noam. 2001. Derivation by phase. In Michael Kenstowicz (ed), Ken Hale: A Live in Language, 1-52. Cambridge, MA: The MIT Press.

Chomsky, Noam. 2008. On Phases. In Robert Freidin, Carlos P. Otero \& Maria-Luisa Zubizaretta (eds.), Foundational Issues in Linguistic Theory, 133-166. Cambridge, MA: The MIT Press.

Christensen, Ken Ramshøj. 2005. Interfaces. Negation-Syntax-Brain. PhD-dissertation. University of Aarhus. Aarhus.

Christensen, Ken Ramshøj. 2008. NEG-shift, Licensing, and Repair Strategies. Studia Linguistica 62(2), 182-223.

Cinque, Guglielmo. 1999. Adverbs and Functional heads. Oxford: Oxford University Press.

Cinque, Guglielmo. 2004. Issues in adverbial syntax. Lingua 114, 683-710. 
Collins, Chris. 2005. A Smuggling Approach to the Passive in English. Syntax 8, 81-120.

COCA. The Corpus of Contemporary American English Online Service. Mark Davies. November-December 2010. http://corpus.byu.edu/coca/

De Clercq, Karen. 2010a. Neg-shift in English. Evidence from PP-adjuncts.' In Duh-Ho An \& Soon-Yeon Kim, Proceedings of the 12th Seoul International Conference on Generative Grammar: 2010 Movement in Minimalism. Seoul: Hankuk Publishing Company.

De Clercq, Karen. 2010b. No in PPs. Evidence for Neg-shift in English. Handout for The Fifth Newcastle-Upon-Tyne Postgraduate Conference in Linguistics. Newcastle. 23rd March 2010.

De Clercq, Karen. 2011a. Negative PP-adjuncts and Scope. Paper presented at ConSOLE XIX. Groningen University, January 5-8 2011.

De Clercq, Karen. 2011b. SQUAT, zero and no/nothing: syntactic negation vs. semantic negation. In Rick Nouwen \& Marion Elenbaas, Linguistics in the Netherlands 2011, 1424. Amsterdam: John Benjamins.

Ernst, Thomas. 2002a. The Syntax of Adjuncts. Cambridge: Cambridge University Press. Ernst, Thomas, 2002b. Adjuncts and Word order asymmetries. In Anna Maria Di Sciullo, Asymmetry in Grammar: Volume I: Syntax and Semantics, 178-207. Amsterdam: John Benjamins.

Frey, Werner \& Karin Pittner. 1998. Zur posiionierung von Adverbialen in deutschen Mittlefeld. Linguistische Berichte 176, 489-534.

Haegeman, Liliane \& Zanuttini, Raffaella. 1991. Negative heads and the NEG-criterion. The Linguistic Review 8, 233-251.

Haegeman, Liliane. 1995. The Syntax of Negation. Cambridge: Cambridge University Press. 
Haegeman, Liliane \& Zanuttini, Raffaella. 1996. Negative Concord in West Flemish. In Adriana Belletti \& Luigi Rizzi (eds), Parameters and Functional Head: Essays in Comparative Syntax, 117-180. Oxford: Oxford University Press.

Haegeman, Liliane. 1997. The syntax of n-words and the NEG criterion. In Danielle Forget, Paul Hirschbühler, France Martineau \& María Luisa Rivero (eds.), Negation and Polarity. Syntax and Semantics, 115-137. Amsterdam: John Benjamins.

Haegeman, Liliane. 2000. Negative Preposing, Negative Inversion and the Split CP. In Laurence Horn \& Yasuhiko Kato (eds.), Negation and Polarity, 29-69. Oxford: Oxford University Press.

Haegeman, Liliane. 2002. Sentence-medial NP-adjuncts in English. Nordic Journal of Linguistics 25(1), 79-108.

Haegeman, Liliane \& Lohndal, Terje. 2010. Negative Concord and Multiple Agree: a Case Study of West Flemish.'Linguistic Inquiry 41(2), 181-211.

Haumann, Dagmar. 2007. Adverb Licensing and Clause Structure in English. Amsterdam: John Benjamins.

Horn, Laurence C. 1989. A Natural History of Negation. Chicago: The University of Chicago Press.

Huddleston, Rodney \& Geoffrey Pullum. 2002. The Cambridge Grammar of the English Language. Cambridge: Cambridge University Press.

Jayaseelan, Karattuparambil. 2008. Topic, focus and adverb positions in clause structure. Nanzan Linguistics 4, 43-68

Jayaseelan, Karattuparambil. 2010. Stacking, stranding, and pied-piping: a proposal about word order. Syntax 13, 298-330.

Jackendoff, Ray. 1977. X’ Syntax: a Study of Phrase Structure. Cambridge, MA: The MIT Press. 
Kato, Yasuhiko. 2000. Interpretive asymmetries of negation. In Laurence Horn \& Yasuhiko Kato (eds.), Negation and Polarity, 62-87. Oxford: Oxford University Press.

Klima, Edward. 1964. Negation in English. In Jerry Fodor \& Jerrold Katz (eds.), The Structure of Language, 246-323. New Jersey: Prentice Hall.

Laka, Itziar. 1990. Negation in Syntax: On the Nature of Functional Categories and Projections. Ph.D. dissertation, MIT, Cambridge, MA.

Lambotte, Paul. 1998. Aspects of Modern English Usage. Paris/ Brussels: De Boeck Université.

McCawley, James D. 1998. The Syntactic Phenomena of English. (2nd edition). Chicago: University of Chicago Press. 2 vols.

McCloskey, James. 2011. Polarity and case-licensing: the cartography of the inflectional layer in Irish. Paper presented at GIST 3: Cartographic structures and beyond. Ghent University, May 14-15 2011.

Moscati Vincenzo. 2006. The scope of Negation. Ph.D. dissertation, Università di Siena Moscati, Vincenzo. 2011. Negation raising: logical form and linguistic variation. Cambridge: Cambridge Scholars Publishing.

Nakajima, Heizo. 1991. Transportability, scope ambiguity of adverbials, and the generalized binding theory. Journal of Linguistics 27, 337-374.

Ota, Akira. 1981. Semantic interpretation of NPs containing no. Sophia Linguistica VII, 1328.

Pittner, Karin. 1999. Adverbiale im Deutschen. Untersuchungen zu ihrer Stellung und Interpretation. Tübingen: Stauffenburg.

Pittner, Karin. 2004. Adverbial positions in the German medialdle field. In Jennifer R. Austin, Stefan Engelberg \& Gisa Rauch (eds,), Adverbials: The interplay between meaning, context and syntactic structure, 253-287. Amsterdam: John Benjamins. 
Progovac, Liliana. 1993. Negative polarity: entailment and binding. Linguistics and Philosophy 20, 149-180.

Progovac, Liliana. 1994. Negative and positive polarity. Cambridge: Cambridge University Press.

Puskas, Genoveva. 2000. Word Order in Hungarian: The Syntax of A'-positions. Amsterdam: John Benjamins.

Quirk, Randolph, Sidney Greenbaum, Geoffrey Leech \& Jan Svartvik. 1985. A Comprehensive Grammar of the English Language. London: Longman.

Rizzi, Luigi. 1997. The fine structure of the left periphery. In Liliane Haegeman (ed.), Elements of Grammar, 289-330. Dordrecht: Kluwer.

Ross, John Robert. 1973. Slifting. In Maurice Gross, Morris Halle \& Marcel Schützenberger, (eds.), The formal analysis of natural languages, 133-169. The Hague: Mouton.

Sinclair, John (ed.). 1990. COBUILD English Grammar. London: Collins.

Sobin, Nicolas. 2003. Negative inversion as nonmovement. Syntax 6, 183-222.

Smith, Neil and Annabel Cormack. 1998. Negation, polarity and V positions in English. $U C L$ working papers in Linguistics 10, 285-322

Swan, Michael. 2005. Practical English Usage. Oxford: Oxford University Press.

Tottie, Gunnel. 1983. Much about not and nothing. A Study of the Variation between Analytic and Synthetic Negation in Contemporary American English. Scripta Minora. Regiae Societatis Humanorum Litterarum Lundensis. CWK Gleerup.

Tubau, Susagna. 2008. Negative Concord in English and Romance: Syntax-Morphology Interface Conditions on the Expression of Negation. Utrecht: LOT.

Zanuttini, Raffaella. 1997. Negation and clausal structure: a comparative study of Romance languages. Oxford: Oxford University Press.

Zeijlstra, Hedde. 2004. Sentential Negation and Negative Concord. Utrecht: LOT. 